Research Article

\section{Metabolic profiling and antibacterial activity of Eryngium pristis Cham. \& Schltdl. - prospecting for its use in the treatment of bacterial infections}

\author{
Laura Silva Fernandes ${ }^{1,2}$, Ygor Ferreira Garcia da Costa ${ }^{1,2}$, Martha \\ Eunice de Bessa ${ }^{2,3}$, Adriana Lucia Pires Ferreira', José Otávio do

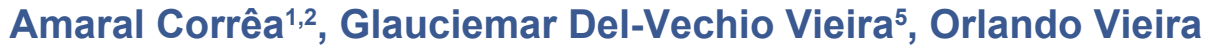 \\ de Sousa ${ }^{1,5}$, Ana Lúcia Santos de Matos Araújo ${ }^{5}$, Paula C \\ Castilho ${ }^{6 *}$ and Maria Silvana Alves ${ }^{1,2 *}$ \\ ${ }^{1}$ Programa de Pós-Graduação em Ciências Farmacêuticas, Universidade Federal de Juiz de Fora, \\ Juiz de Fora, Minas Gerais, Brazil \\ ${ }^{2}$ Laboratório de Bioatividade Celular e Molecular, Universidade Federal de Juiz de Fora, Juiz de \\ Fora, Minas Gerais, Brazil \\ ${ }^{3}$ Laboratório de Produtos Naturais Bioativos, Departamento de Bioquímica, Instituto de Ciências \\ Biológicas, Universidade Federal de Juiz de Fora, Minas Gerais, Brazil \\ ${ }^{4}$ Laboratório de Bacteriologia, Serviço de Patologia Clínica, Hospital Universitário Clementino Fraga \\ Filho, Universidade Federal do Rio de Janeiro, Rio de Janeiro, Rio de Janeiro, Brazil \\ ${ }^{5}$ Laboratório de Química Biomedicinal e Farmacologia Aplicada, Universidade Federal de Juiz de \\ Fora, Juiz de Fora, Minas Gerais, Brazil \\ ${ }^{6}$ Centro de Química da Madeira (CQM), Departamento de Química, Faculdade de Ciências Exatas \\ e Engenharias, Universidade da Madeira, Campus da Penteada, Funchal, Portugal
}

\section{Abstract}

Morbidity and mortality of the infected patients by multidrug-resistant bacteria have increased, emphasizing the urgency of fight for the discovery of new innovative antibiotics. In this sense, natural products emerge as valuable sources of bioactive compounds. Among the biodiversity, Eryngium pristis Cham. \& Schltdl. (Apiaceae Lindl.) is traditionally used to treat thrush and ulcers of throat and mouth, as diuretic and emmenagogue, but scarcely known as an antimicrobial agent. With this context in mind, the goals of this study were to investigate the metabolic profile and the antibacterial activity of ethanolic extract (EE-Ep) and hexane (HF-Ep), dichloromethane (DF-Ep), ethyl acetate (EAF-Ep) and butanol (BF-Ep) fractions from E. pristis leaves. Gas Chromatography-Mass Spectrometry (GC-MS) was performed to stablish the metabolic profile and revealed the presence of 12 and 14 compounds in EAF-Ep and HF-Ep, respectively. $\beta$-selinene, spathulenol, globulol, 2-methoxy-4-vinylphenol, $\alpha$-amyrin, $\beta$-amyrin, and lupeol derivative were some of phytochemicals identified. The antibacterial activity was determined by Minimal Inhibitory Concentration (MIC) using the broth micro-dilution against eight ATCC $^{\circledR}$ and five methicillin-resistant Staphylococcus aureus (MRSA) clinical strains. HF-Ep was the most effective (MIC $\leq$ $5,000 \mu \mathrm{g} / \mu \mathrm{L}$ ), being active against the largest part of tested Gram-positive and Gram-negative bacterial strains, including MRSA, with exception of Escherichia coli (ATCC 25922) and Pseudomonas aeruginosa (ATCC 9027) and (ATCC 27853). These results suggest that E. pristis is a natural source of bioactive compounds for the search of new antibiotics which can be an interesting therapeutic approach to recover patients mainly infected by MRSA strains.

Graphical abstract

\section{More Information}

*Address for Correspondence:

Profa. Dra. Maria Silvana Alves, Laboratório de Bioatividade Celular e Molecular, Centro de Pesquisas Farmacêuticas, Departamento de Ciências Farmacêuticas, Faculdade de Farmácia, Universidade Federal de Juiz de Fora, Rua José Lourenço Kelmer $s / n^{\circ}$, Campus Universitário, Bairro São Pedro, Juiz de Fora, Minas Gerais, CEP 36.036-900, Brazil, Email: silvana.alves@ufjf.edu.br

ORCiD: orcid.org/0000-0002-9153-2402

Profa. Dra. Paula Castilho, Centro de Química da Madeira (CQM), Departamento de Química, Faculdade de Ciências Exatas e Engenharias, Universidade da Madeira, Campus da Penteada, Funchal, 9000-390, Portugal, Email: castilho@uma.pt

ORCiD: orcid.org/0000-0002-8303-4286

Submitted: October 25, 2021

Approved: November 02, 2021

Published: November 03, 2021

How to cite this article: Fernandes LS, da Costa YFG, de Bessa ME, Ferreira ALP, do Amaral Corrêa JO, et al. Metabolic profiling and antibacterial activity of Eryngium pristis Cham. \& Schltdl. - prospecting for its use in the treatment of bacterial infections. Arch Pharm Pharma Sci. 2021; 5: 020-028.

\section{DOI: 10.29328/journal.apps. 1001027}

Copyright License: (๐ 2021 Fernandes LS, et al This is an open access article distributed under the Creative Commons Attribution License, which permits unrestricted use, distribution, and reproduction in any medium, provided the original work is properly cited.

Keywords: Eryngium pristis, Apiaceae, anti bacterial activity, bacterial resistance, Staphy lococcus aureus, Methicillin-resistant Staphy lococcus aureus

Highlights

- Eryngium pristis was active against Grampositive and Gram-negative bacteria;

- EAE-Ep and HE-Ep possess antibiotic active compounds:

- E. pristis can treat infections due to methicillin-resistant Staphylococcus aureus.

Check for updates

OPEN ACCEss

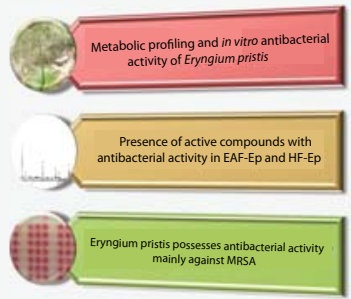




\section{Abbreviations}

AMP: Ampicillin; AMR: Antimicrobial Resistance; AR: Anti bacterial (Antibiotic) Resistance; ATCC ${ }^{\circledR}$ : American Type Culture Collection; BF-Ep: Butanol Fraction from Eryngium pristis leaves; CHL: Chloramphenicol; CLSI: Clinical and Laboratory Standards Institute; DF-Ep: Dichloromethane Fraction from Eryngium pristis leaves; E. coli: Escherichia coli; E. pristis: Eryngium pristis; EAF-Ep: Ethyl Acetate Fraction from Eryngium pristis leaves; EE-Ep: Ethanolic Extract from Eryngium pristis leaves; EI: Electron Ionization; FIOCRUZ: Fundação Oswaldo Cruz; GC-MS: Gas Chromatography-Mass Spectrometry; HF-Ep: Hexane Fraction from Eryngium pristis leaves; INCQS: Instituto Nacional de Controle de Qualidade em Saúde; MBC: Minimal Bactericidal Concentration; MDR: Multidrug Resistant; MHA: Müeller-Hinton Agar; MHB: Müeller-HintonBroth; MIC: Minimal Inhibitory Concentration; MRSA: Methicillin-resistant Staphylococcus aureus; NIST: National Institute of Standards and Technology; NPs: Natural Products; P. aeruginosa: Pseudomonas aeruginosa; Rt: Retention index; S. aureus: Staphylococcus aureus; Salmonella Choleraesuis: Salmonella enterica subsp. enterica serovar Choleraesuis; Salmonella Typhi: Salmonella enterica subsp. enterica serovar Typhi; Salmonella Typhimurium: Salmonella enterica subsp. enterica serovar Typhimurium; SISGEN: National System for Management of Genetic Heritage; TTC: 2,3,5-Triphenyl Tetrazolium Chloride; UTI: Urinary Tract Infection; WHO: World Health Organization

\section{Introduction}

Antimicrobial resistance (AMR) happens when microorganisms (bacteria, fungi, virus, and parasites) change when they are exposed to antimicrobial agents (antibiotics, antifungals, antivirals, antimalarials, and anthelmintics) [1]. This natural phenomenon occurs, over the time, usually through genetic variations, but the misuse and overuse of these medicines is accelerating the occurrence of the AMR, and the selective pressure caused by them favors this process and causes the development of a diversity of resistance mechanisms [1-3]. Unfortunately, the reduction of the antibiotic effectiveness to treat bacterial infections, for example, results in prolonged hospitalization and increased health care costs and death, reflecting on serious consequences for society and economy $[1,4,5]$.

Historically, the antibiotics discovery revolutionized the modern medicine, enabling the success of invasive clinical procedures and saving millions of human lives [4]. Despite these benefits, severe cases of infectious diseases mainly caused by multidrug-resistant (MDR) bacteria have increased worldwide reaching at an alarming rate $[4,6]$. It is noteworthy that the antibacterial (antibiotic) resistance (AR) can be understood as the bacteria ability to multiply in the presence of therapeutic doses of antibiotics since these substances lose their capacity to effectively inhibit the bacterial growth $[4,6]$. In function of these difficulties, alternative antimicrobial researches have been important for the discovery of more targeted treatment strategies, including therapies employed before the advent of antibiotics. To fulfill these goals, there has been a return to traditional medicines and non-conventional practices, being the medicinal and smelling plants essential pillars of healthcare and traditional medicinal systems globally used [7].

In this sense, world health is experiencing a duality: on the one hand, the increase of AMR, and on the other hand, the insufficient pipeline of drug development to combat this threat. Considering the challenge of finding new antibiotics [4], natural products (NPs), defined as secondary metabolites produced by plants, microorganisms, insects and various marine organisms [8], have been an alternative and reasonable approach to research, discovery and development of innovative antibacterial agents due to its diversity of bioactive compounds or complexes [9]. Newman and Cragg [10] reported that all of 1,881 drugs approved from 1981 to 2019, 787 (41.8\%) of them are NPs or their derivatives. Following this way, the recent discovery of the antituberculosis tuberlactomicin A and caprazamycins and the anti-methicillin-resistant Staphylococcus aureus (MRSA) amycolamicin encourage the researchers to continuously investigate the antibacterial potential of NPs mainly against MDR microorganisms [11]. In this scenario, many new molecules have been identified and/or developed based on the scientific advancement; the random screening of plants and from sharp-eyed observations of scientists, and these approaches demonstrated the antibiotic potential of phytochemicals when used alone and/or as synergists or potentiators of other natural or synthetic therapeutic options [12-14].

Among the incredible and immense global biodiversity, Eryngium L. is the largest and most complex representative genus of the Apiaceae Lindl. Family with about 250 plant species worldwide distributed [15], being also observed in the Southern and Southeastern regions of Brazil [16]. In this continental Latin American country, research on NPs is favored due to its wide biodiversity [17], but despite this fact and the several Brazilian academic publications about plants in respectable international journals, few patents and medicines have been derived from these studies [18], encouraging to perform this kind of investigation. Traditionally, Eryngium species have been used as anti-inflammatory, antitussive, aphrodisiac, diuretic, hypoglycemic, stimulant and in the treatment of bladder and kidney dysfunctions, digestive disorders, diarrhea and gastrointestinal problems, headache and toothache, snakebites, and venereal diseases [15]. Pharmacologically, these plants possess anticonvulsant, antiinflammatory, antimalarial, anthelmintic and antimicrobial activities and analgesic property, being also described as diuretic and bronchodilator and used in the treatment of skin disorders [19-22]. 
Among these plant species, Eryngium pristis Cham. \& Schltdl. is a native South America shrub mainly observed in Bolivia and Brazil, being popularly known in this last country as "língua-de-tucano" and traditionally used as emmenagogue and diuretic and to treat throat inflammation and mouth ulcers and canker sores [16]. This medicinal plant was initially recorded in Brazil in 1874 by Chernoviz, when this Polish physician described, in details, information about the efficacy and preparation of the remedies from each plant studied, including this one, in his book "Formulary and Medical Guide" [23]. After this first description, E. pristis has been poorly chemically and biologically scientific exploited, mainly under the microbiological viewpoint.

With this context in mind, the present study aimed to investigate the in vitro antibacterial potential of ethanolic extract (EE-Ep) and hexane (HF-Ep), dichloromethane (DFEp), ethyl acetate (EAF-Ep) and butanol (BF-Ep) fractions obtained from E. pristis leaves against eight Gram-positive (two) and Gram-negative (six) ATCC ${ }^{\circledR}$ and five MRSA clinical strains. Additionally, the most active samples were chemically characterized to establish their metabolic profiles and to contribute for the better understanding of the possible antibacterial activity of this medicinal plant.

\section{Results and discussion}

One of the most important factors for the discovery of natural active ingredients that can be useful for human resources consists mainly of the interaction between che mistry and pharmacology [24], making the chemical chara cterization of extracts and fractions obtained from medicinal plants a crucial step during the scientific investigation.

According to Daneshzadeh, et al. [27], plants belonging to Apiaceae family are aromatic; monoterpene, sesquiterpene, phenyl compounds and related resins producers; and possess antimicrobial potential. Taking into account that Eryngium is the most relevant genus of this family as previously mentioned, its antimicrobial potential, and the promising application of NPs to research, discovery and development of new antibiotics, the in vitro antibacterial activity of $E$. pristis against eight ATCC $^{\circledR}$ and five MRSA clinical strains by the determination of the Minimal Inhibitory Concentration (MIC) was investigated, as aforementioned.

As shown by Tables 1 and 2, with exception of DF-Ep and BF-Ep, the extract (EE-Ep) and the other fractions (HFEp and EAF-Ep) were active against $S$. aureus (ATCC 6538) and (ATCC 29213) and five MRSA clinical strains, with MIC values ranging from 1,250 to $5,000 \mu \mathrm{g} / \mathrm{mL}$. It is also possible to note the bactericidal effect obtained with EE-Ep against S. aureus (ATCC 6538) and (ATCC 29213) and EAF-Ep against $S$. aureus (ATCC 6538). According to these data, it is possible to clearly note that EE-Ep, HF-Ep and EAF-Ep were particularly more active against $S$. aureus, with bactericidal effect, than with the other strains tested, probably avoiding a selective pressure under them. Thiem, et al. [28] reported the antimicrobial activity of ethanolic extracts from leaves and roots of Eryngium planum, Eryngium campestre and Eryngium maritimum against S. aureus $\left(\right.$ ATCC $^{\circledR} 29213^{\text {im }}$ ), with MIC values ranging from 400 to $1,900 \mu \mathrm{g} / \mathrm{mL}$, that are in accordance with the present obtained results. HF-Ep was also active against Escherichia coli (ATCC 10536) (MIC = 2,500 $\mu \mathrm{g} / \mathrm{mL}$ ), Salmonella Choleraesuis (ATCC 10708) (MIC $=5,000 \mu \mathrm{g} / \mathrm{mL}$ ) and Salmonella Typhimurium (ATCC 13311) (MIC $=5,000 \mu \mathrm{g} / \mathrm{mL}$ ), demonstrating its ability to inhibit the growth of both Gram-positive and Gram-negative bacteria. Sadiq, et al. [29] evaluated the antibacterial potential of methanolic extract and hexane, chloroform, ethyl acetate and aqueous fractions of Eryngium caeruleum aerial parts against $E$. coli [isolated from urinary tract infection (UTI)] and Salmonella Typhi (isolated from stools), among others, and reported MIC values ranging from $316.64 \pm 0.31$ (hexane fraction) to $846.35 \pm 3.63$ (aqueous fraction) $\mu \mathrm{g} / \mathrm{mL}$ and from $556.32 \pm 3.66$ (ethyl acetate fraction) to $983.64 \pm$ 6,440 (aqueous fraction) $\mu \mathrm{g} / \mathrm{mL}$, in this order. None of the tested extract and fractions of $E$. pristis were able to inhibit E. coli (ATCC ${ }^{\circledR} 25922^{\text {Tm}}$ ) and P. aeruginosa $\left(\right.$ ATCC $^{\circledR} 9027^{\text {Tm}}$ ) and (ATCC $^{\circledR} 27853^{\text {TM' }}$ ).

Despite the MIC values determined in this study $(1,250$ to $5,000 \mu \mathrm{g} / \mathrm{mL}$ ) that classified the antibacterial activity as weak according to Kuete [significant (MIC < $100 \mu \mathrm{g} / \mathrm{mL}$ ), moderate $(100<$ MIC $=625 \mu \mathrm{g} / \mathrm{mL})$ or weak $(\mathrm{MIC}>625 \mu \mathrm{g} /$ $\mathrm{mL}$ )] [30], it is crucial to point out that EE-Ep, HF-Ep and EAF-Ep were active against the five MRSA clinical strains evaluated, isolated from blood (hemoculture) of infected patients and resistant to several antibiotics used in the clinical practice to treat these microorganisms and tested in the laboratorial routine, corroborating the relevance of the antibacterial effect of $E$. pristis. In addition, biofilm-forming S. aureus (ATCC ${ }^{\circledR} 6538^{\text {iw) }}$ ) and biofilm-forming E. coli (ATCC $^{\circledR}$ $10536^{\text {TM }}$ ) were included because biofilms play an important role in infectious diseases and their persistence [31], among other functions, and during its formation, various bacterial species communicate with one another through quorum sensing signaling systems [32]. In this way, HF-Ep was active against these two strains and maybe this fraction can also inhibit the biofilm formation, which is associated with about $65 \%$ of all bacterial infections [32]. Moreover, it is noteworthy that the World Health Organization (WHO) recommends that the research, discovery and development strategies should be urgently focused on new antibiotics active against multi- and extensively drug-resistant Gramnegative bacteria responsible for acute clinical infections in both hospital and community settings worldwide [33]. In this sense, and as presented above, HF-Ep was also active against E. coli $(\mathrm{MIC}=2,500 \mu \mathrm{g} / \mathrm{mL}$ ) and Salmonella species $(\mathrm{MIC}=$ $5,000 \mu \mathrm{g} / \mathrm{mL}$ ), two Enterobacteriaceae members belonging to the critical and high priority groups according to the WHO global priority pathogens list, in this order, when these 
Table 1: Minimal inhibitory concentration (MIC) values obtained with ethanolic extract (EE-Ep) and hexane (HF-Ep) and dichloromethane (DF-Ep) fractions of Eryngium pristis leaves and the antibiotics ampicillin (AMP) and chloramphenicol $(\mathrm{CHL})$ against bacterial strains tested

\begin{tabular}{|c|c|c|c|c|c|}
\hline \multirow{2}{*}{ Bacterial Strain } & \multicolumn{5}{|c|}{ MIC ( $\mu \mathrm{g} / \mathrm{mL})$} \\
\hline & EE-Ep & HF-Ep & DF-Ep & CHL* $^{*}$ & AMP* \\
\hline Staphylococcus aureus (ATCC ${ }^{\circledR} 6538^{T M}$ ) & $5000^{1}$ & $1250^{2}$ & $>5000$ & $8^{c}$ & $<4^{a}$ \\
\hline Staphylococcus aureus (ATCC ${ }^{\circledR} 29213^{\text {Th }}$ ) & $2500^{1}$ & $2500^{2}$ & $>5000$ & $8^{c}$ & $<4^{a}$ \\
\hline Escherichia coli (ATCC ${ }^{\circledR} 10536^{\mathrm{TM}}$ ) & $>5000$ & $2500^{2}$ & $2500^{2}$ & $<4^{\mathrm{c}}$ & $<4^{\mathrm{b}}$ \\
\hline Escherichia coli (ATCC $\left.{ }^{\circledR} 25922^{T \mu}\right)$ & $>5000$ & $>5000$ & $>5000$ & $<4^{\mathrm{c}}$ & $<4^{b}$ \\
\hline Salmonella Choleraesuis (ATCC ${ }^{\circledR} 10708^{\text {TM }}$ ) & $5000^{2}$ & $5000^{2}$ & $>5000$ & $<4^{\mathrm{c}}$ & $<4^{\mathrm{b}}$ \\
\hline Salmonella Typhimurium (ATCC ${ }^{\otimes} 13311^{\text {Tn }}$ ) & $>5000$ & $5000^{2}$ & $5000^{2}$ & $<4^{\mathrm{c}}$ & $<4^{\mathrm{b}}$ \\
\hline Pseudomonas aeruginosa $\left(\right.$ ATCC $^{\circledR} 9027^{\text {TM }}$ ) & $>5000$ & $>5000$ & $>5000$ & 64 & $>500$ \\
\hline Pseudomonas aeruginosa $\left(\right.$ ATCC $^{\circledR} 27853^{\text {тM }}$ ) & $>5000$ & $>5000$ & $>5000$ & 64 & $>500$ \\
\hline MRSA 1485279 & $5000^{2}$ & $5000^{2}$ & $>5000$ & $125^{c}$ & $250^{a}$ \\
\hline MRSA 1605677 & $2500^{2}$ & $5000^{2}$ & $5000^{2}$ & $8^{c}$ & $125^{\mathrm{a}}$ \\
\hline MRSA 1664534 & $2500^{2}$ & $2500^{2}$ & $5000^{2}$ & $8^{c}$ & $125^{\mathrm{a}}$ \\
\hline MRSA 1688441 & $5000^{2}$ & $5000^{2}$ & $>5000$ & $8^{c}$ & $500^{a}$ \\
\hline MRSA 1830466 & $2500^{2}$ & $2500^{2}$ & $5000^{2}$ & $8^{c}$ & $250^{\mathrm{a}}$ \\
\hline
\end{tabular}

MRSA: methicillin-resistant Staphylococcus aureus; MIC > 5,000 $\mu \mathrm{g} / \mathrm{mL}$ was not determined because it was above the highest concentration tested; ${ }^{*} \mathrm{MIC}$ values obtained with AMP and CHL agreed with the quality control intervals reported for non-fastidious organisms by CLSI (2014), according to the document M100-S24: AMP (Penicillin) (a) MIC $\leq 0.12$ and $\geq 0.25 \mu \mathrm{g} / \mathrm{mL}$ classify these bacteria as sensitive and resistant, respectively, AMP (b) MIC $\leq 8,16$ and $\geq 32 \mu \mathrm{g} / \mathrm{mL}$ as sensitive, intermediate and resistant, in this order, and $\mathrm{CHL}$ (c) $\mathrm{MIC} \leq 8,16$ and $\geq 32 \mu \mathrm{g} / \mathrm{mL}$ as sensitive, intermediate and resistant, respectively; 1: bactericidal effect; and 2: bacteriostatic effect.

Table 2: Minimal inhibitory concentration (MIC) values obtained with ethyl acetate (EAF-Ep) and butanol (BF-Ep) fractions of Eryngium pristis leaves and the antibiotics ampicillin (AMP) and chloramphenicol ( $\mathrm{CHL})$ against bacterial strains tested.

\begin{tabular}{|c|c|c|c|c|}
\hline \multirow{2}{*}{ Bacterial Strain } & \multicolumn{4}{|c|}{ MIC ( $\mu \mathrm{g} / \mathrm{mL})$} \\
\hline & EAF-Ep & BF-Ep & $\mathrm{CHL}^{*}$ & AMP* \\
\hline Staphylococcus aureus (ATCC ${ }^{\circledR} 6538^{\text {TM }}$ ) & $2500^{1}$ & $>5000$ & $8^{c}$ & $<4^{\mathrm{a}}$ \\
\hline Staphylococcus aureus (ATCC ${ }^{\circledR} 29213^{\text {TM }}$ ) & $5000^{2}$ & $>5000$ & $8^{c}$ & $<4^{\mathrm{a}}$ \\
\hline Escherichia coli (ATCC ${ }^{\circledR} 10536^{\text {TM }}$ ) & $>5000$ & $>5000$ & $<4^{c}$ & $<4^{b}$ \\
\hline Escherichia coli (ATCC ${ }^{\circledR} 25922^{T \omega}$ ) & $>5000$ & $>5000$ & $<4^{c}$ & $<4^{\text {b }}$ \\
\hline Salmonella Choleraesuis (ATCC ${ }^{\circledR} 10708^{\mathrm{Tm}}$ ) & $>5000$ & $>5000$ & $<4^{c}$ & $<4^{\mathrm{b}}$ \\
\hline Salmonella Typhimurium (ATCC ${ }^{\circledR} 13311^{\mathrm{TM}}$ ) & $>5000$ & $>5000$ & $<4^{c}$ & $<4^{b}$ \\
\hline Pseudomonas aeruginosa (ATCC ${ }^{\circledR} 9027^{\mathrm{T \mu}}$ ) & $>5000$ & $>5000$ & 64 & $>500$ \\
\hline Pseudomonas aeruginosa (ATCC ${ }^{\circledR} 27853^{\text {TM }}$ ) & $>5000$ & $>5000$ & 64 & $>500$ \\
\hline MRSA 1485279 & $2500^{2}$ & $>5000$ & $125^{c}$ & $250^{\mathrm{a}}$ \\
\hline MRSA 1605677 & $2500^{2}$ & $5000^{2}$ & $8^{c}$ & $125^{\mathrm{a}}$ \\
\hline MRSA 1664534 & $1250^{2}$ & $>5000$ & $8^{c}$ & $125^{a}$ \\
\hline MRSA 1688441 & $2500^{2}$ & $>5000$ & $8^{c}$ & $500^{a}$ \\
\hline MRSA 1830466 & $1250^{2}$ & $5000^{2}$ & $8^{c}$ & $250^{a}$ \\
\hline
\end{tabular}

MRSA: methicillin-resistant Staphylococcus aureus; MIC $>5,000 \mu \mathrm{g} / \mathrm{mL}$ was not determined because it was above the highest concentration tested; *MIC values obtained with AMP and CHL agreed with the quality control intervals reported for non-fastidious organisms by CLSI (2014), according to the document M100-S24: AMP (Penicillin) (a) MIC $\leq 0.12$ and $\geq 0.25 \mu \mathrm{g} / \mathrm{mL}$ classify these bacteria as sensitive and resistant, respectively, AMP (b) MIC $\leq 8,16$ and $\geq 32 \mu \mathrm{g} / \mathrm{mL}$ as sensitive, intermediate and resistant, in this order, and $\mathrm{CHL}$ (c) $\mathrm{MIC} \leq 8,16$ and $\geq 32 \mu \mathrm{g} / \mathrm{mL}$ as sensitive, intermediate and resistant, respectively; 1: bactericidal effect; and 2: bacteriostatic effect.

strains express certain resistance markers, reinforcing the antibacterial potential of this medicinal plant [30].

In this context, HF-Ep and EAF-Ep, the most effective fractions selected among those samples microbiologically investigated as will be described in detail below, were characterized by Gas Chromatography-Mass Spectrometry (GC-MS) to establish their chemical profiles of constituents. The phytochemicals were initially identified comparing their retention index (Rt) with those noted in the literature. Below, will be present the results, showing the phytochemicals detected and identified from the two mainly fractions, HF-Ep and EAF-Ep, obtained from E. pristis.

As shown by Figure 1 and Table 3, when GC-MS was applied to characterize HF-Ep, 16 compounds ( 1 - 16 peaks) were detected, totalizing $77.5 \%$. In this sample, the main components identified were lupeol derivative (29.94\%), $\alpha$-amyrin (18.87\%), ethyl linolenate (5.79\%), pentadecanoic acid ethyl ester (4.78\%) and $\beta$-amyrin (4.16\%) (Table 3).
The same procedure was carried out to characterize EAF-Ep, and 12 compounds ( 1 - 12 peaks) were detected as displayed by Figure 2 and Table 4, totaling 75.0\% of the identified oxygenated volatile substances. Among the main compounds identified coumaran (2,3-dihydrobenzofuran) (36.22\%), adipic acid derivative (9.07\%), blumenol C (4.52\%), D-allose (3.70\%) and 2-methoxy-4-vinylphenol (2.99\%) were highlighted.

Tables 3 and 4 present the chemical compounds identified by GC-MS from HF-Ep and EAF-Ep, in this order. As aforementioned, E. pristis has been scarcely chemically and biologically investigated, and according to the literature obtained from Medline, PubMed, Science Direct, Scopus, Web of Science, and Google Scholar, with exception of one original article related to the chemical composition of this plant species published by our research group [16], other literature data describing its phytochemicals and biological activities do not exist. In the previous article, the authors 


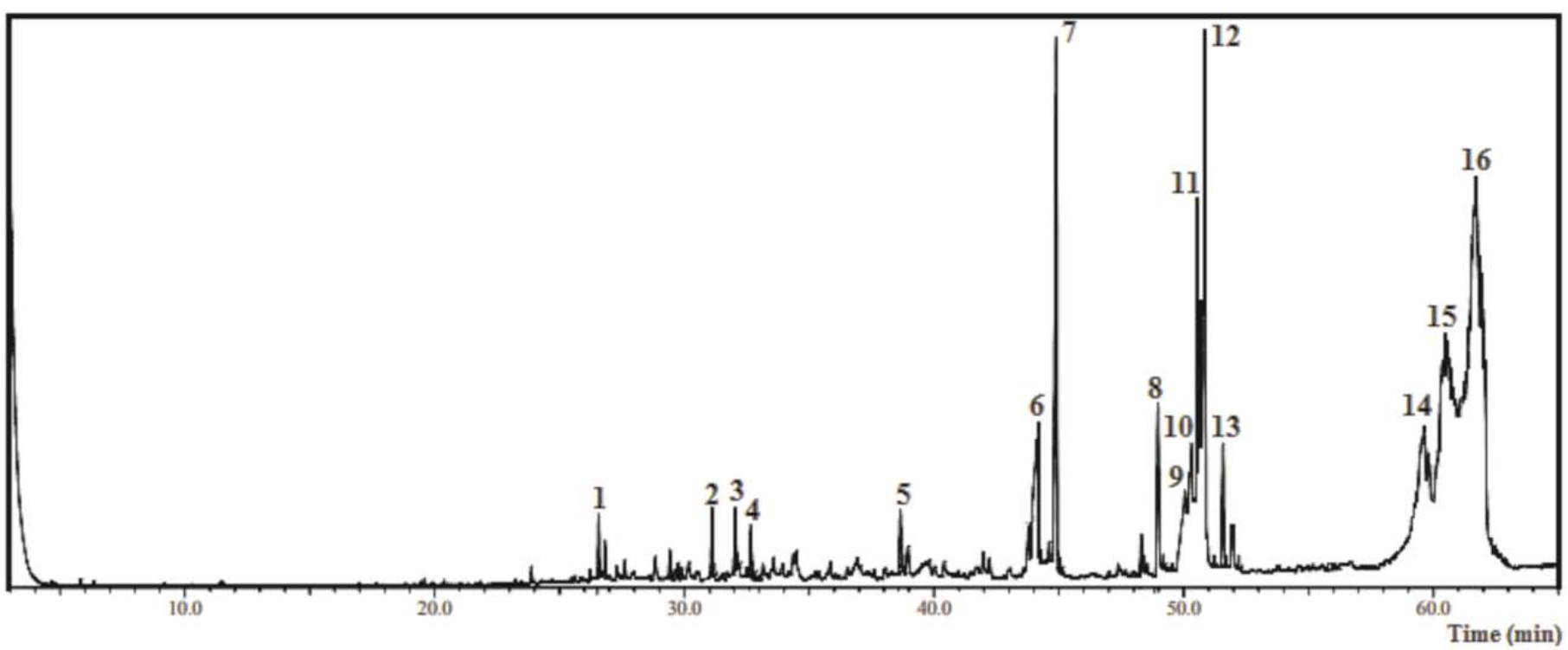

Figure 1: Chromatogram from the Gas Chromatography-Mass Spectrometry analysis of the ethyl acetate fraction obtained from Eryngium pristis leaves (EAF-Ep).

Table 3: Chemical compounds identified by Gas Chromatography-Mass Spectrometry from the hexane fraction of Eyngium pristis leaves (HF-Ep).

\begin{tabular}{|c|c|c|c|c|c|}
\hline $\mathbf{N}^{\circ}$ & Compound & CAS & $\mathbf{R I}_{\exp }$ & $\%$ relative & $\mathrm{m} / \mathbf{z}^{\mathrm{a}}$ \\
\hline 1 & $\beta$-selinene & $17066-67-0$ & 1441 & 0.28 & $204 ; 105 ; 107 ; 93 ; 81 ; 41$ \\
\hline 2 & Spathulenol & $6750-60-3$ & 1639 & 0.41 & $220 ; 205 ; 159 ; 119 ; 91 ; 43$ \\
\hline 3 & Globulol & $51371-47-2$ & 1666 & 0.41 & $222 ; 204 ; 109 ; 81 ; 69 ; 43$ \\
\hline 4 & Eudesma-7(11)-en-4-ol & $473-04-1$ & 1684 & 0.30 & $222 ; 204 ; 189 ; 161 ; 81 ; 43$ \\
\hline 5 & 1-Octadecyne & $629-89-0$ & 1839 & 0.41 & $224 ; 109 ; 95 ; 81 ; 67 ; 43$ \\
\hline 6 & Hexadecanoic acid & $57-10-3$ & 1981 & 2.92 & $256 ; 213 ; 129 ; 73 ; 60 ; 43$ \\
\hline 7 & Pentadecanoic acid ethyl ester & $41114-00-5$ & 1999 & 4.78 & $270 ; 101 ; 88 ; 43$ \\
\hline 8 & Linolenic acid & $463-40-1$ & 2117 & 1.34 & $278 ; 108 ; 93 ; 79 ; 67 ; 55 ; 41$ \\
\hline 9 & Linoleic acid & $60-33-3$ & 2151 & 1.61 & $280 ; 110 ; 95 ; 81 ; 67 ; 55 ; 41$ \\
\hline 10 & Linolenic acid derivative & $301-00-8$ & 2159 & 2.15 & $292 ; 108 ; 93 ; 79 ; 67 ; 55 ; 41$ \\
\hline 11 & Linoleic acid derivative & $112-63-0$ & 2168 & 3.13 & $294 ; 109 ; 95 ; 81 ; 67 ; 55 ; 41$ \\
\hline 12 & Ethyl linolenate & $191-41-9$ & 2175 & 5.79 & $306 ; 108 ; 95 ; 79 ; 67 ; 55 ; 41$ \\
\hline 13 & Stearic acid derivative & $111-61-5$ & 2198 & 0.95 & $312 ; 269 ; 157 ; 101 ; 88 ; 41$ \\
\hline 14 & alpha-Amyrin & $638-95-9$ & 2873 & 18.87 & $426 ; 218 ; 203 ; 189$ \\
\hline 15 & beta-Amyrin & $559-70-6$ & 2886 & 4.16 & $426 ; 218 ; 203 ; 189 ; 69 ; 41$ \\
\hline 16 & Lupeol derivative & $1617-68-1$ & 2987 & 29.94 & $468 ; 218 ; 189 ; 109 ; 95 ; 43$ \\
\hline Total & & & & 77.45 & \\
\hline
\end{tabular}

Table 4: Chemical compounds identified by Gas Chromatography-Mass Spectrometry from the ethyl acetate fraction of Eyngium pristis leaves (EAF-Ep).

\begin{tabular}{|c|c|c|c|c|c|}
\hline $\mathbf{N}^{\circ}$ & Compound & CAS & $\mathbf{R} \mathbf{I}_{\text {exp }}$ & $\%$ relative & $m / z^{a}$ \\
\hline 1 & Coumaran (2,3-dihydrobenzofuran) & $496-16-2$ & 1321 & 36.22 & $120 ; 91 ; 63 ; 39$ \\
\hline 2 & 2-Methoxy-4-vinylphenol & $7786-61-0$ & 1364 & 2.99 & $150 ; 135 ; 107 ; 77$ \\
\hline 3 & Non-identified & - & - & - & - \\
\hline 4 & D-Allose & $2595-97-3$ & 1521 & 3.70 & $180 ; 144 ; 97 ; 73 ; 60$ \\
\hline 5 & Blumenol C & $36151-02-7$ & 1717 & 4.52 & $210 ; 150 ; 135 ; 108 ; 93 ; 69 ; 41$ \\
\hline 6 & 9-Octadecenol & $143-28-2$ & 1839 & 1.78 & $249 ; 123 ; 109 ; 95 ; 81 ; 67 ; 41$ \\
\hline 7 & Oxygenated sesquiterpene & $0-00-0$ & 1847 & 0.80 & $292 ; 192 ; 147 ; 119 ; 57$ \\
\hline 8 & Non-identified & - & - & - & - \\
\hline 9 & Non-identified & - & - & - & - \\
\hline 10 & Stearic acid & $57-11-4$ & 2167 & 2.77 & $283 ; 185 ; 129 ; 73 ; 60 ; 41$ \\
\hline 11 & Oleic Acid derivative & $112-80-1$ & 2175 & 2.86 & $282 ; 97 ; 69 ; 55 ; 27 ; 41$ \\
\hline 12 & Adipic acid derivative & $141-18-4$ & 2297 & 9.07 & $273 ; 173 ; 155 ; 85 ; 57 ; 41$ \\
\hline Total & & & & 79.49 & \\
\hline
\end{tabular}




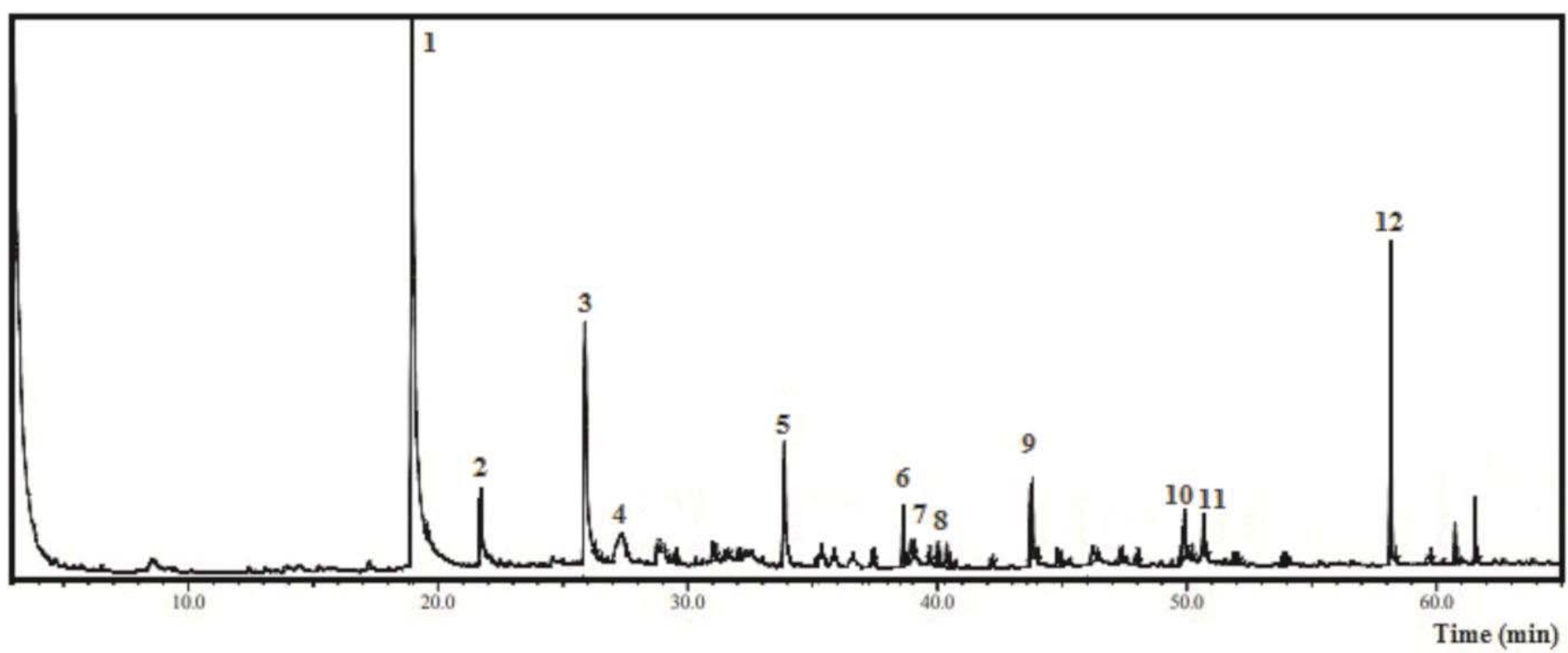

Figure 2: Chromatogram from the Gas Chromatography-Mass Spectrometry analysis of the hexane fraction obtained from Eryngium pristis leaves (HF-Ep).

performed the phytochemical screening and detected the presence of tannin, flavonoid, coumarin, terpenoid and steroid, saponin and alkaloid classes [16]. Erdem, et al. [15] reported that the aerial parts of Eryngium species possess mainly saponins, flavonoids, and essential oil, corroborating the previous findings. These authors also described in their revision that underground parts of these plants contain triterpene saponins, monoterpene glycosides, phenolic compounds such as flavonoids and phenolic acids, coumarin derivatives, terpene aldehyde esters, acetylenes, essential oil, and oligosaccharides [15].

Qualitatively, some compounds noted in Tables 3 and 4 were anteriorly described in other species of Eryngium. For example, spathulenol, hexadecanoic acid, ethyl hexadecanoate and falcarinol were identified by Karimi, et al. [25] using GC-MS analysis of $n$-hexane extracts and fractions from E. caeruleum and Eryngium thyrosoideum aerial parts. $\beta$-selinene, spathulenol, and globulol can also be observed in Eryngium species using The Essential Oil Database [26].

Under the chemical viewpoint, some compounds such as saponins [34] and polyacetylenes [35] identified in Eryngium have been reported to possess antibacterial activity, but we cannot extrapolate this data to all species of this genus, and we must deepen these investigations mainly in scarcely studied medicinal plants like E. pristis.

As showed by Table 4, 2-methoxy-4-vinylphenol, an aromatic substance, was detected in EAF-Ep (peak 2), which was anteriorly identified, among others phytochemicals, in a crude extract of Ocimum tenuiflorum Linn leaves that was active against $S$. aureus, Staphylococcus epidermidis and Propionibacterium acnes. In this patent, the inventors claimed for the isolation and identification of bioactive compounds from this plant to treat acne vulgaris caused by these microorganisms [36]. $\beta$-selinene, a sesquiterpene hydrocarbon detected in HFEp (Table 3; peak 1), was described as active against $S$. aureus (ATCC 6538P) (MIC $=500 \mu \mathrm{g} / \mathrm{mL}$ ) and Escherichia coli (IFO 3301) (MIC $=1000 \mu \mathrm{g} / \mathrm{mL})$, and inactive against Pseudomonas aeruginosa (IFO 3080) [37]. In addition, Tan, et al. [38], when investigating the fruits of Eucalyptus globulus Labill, reported the antimicrobial activity of globulol, a sesquiterpene derivative also identified in HF-Ep (Table 3, peak 3), but these authors did not evaluate none of the strains tested in the present study.

Table 3 displayed that falcarinol, a polyene, was detected in HF-Ep (peak 26). This compound was previously demonstrated as microbiologically active against $S$. aureus and E. coli, among other microorganisms, by Kobaisy, et al. [39].

Together, the chemical and microbiological results demonstrate the antibacterial activity of E. pristis and its potential to threat bacterial infections, mainly caused by MRSA strains. The most efficiency of HF-Ep can be explained by the presence of some compounds such as $\beta$-selinene, globulol and falcarinol, detected only in this fraction. It is noteworthy that species of Eryngium is traditionally used to treat wounds and ulcers and that Staphylococcus aureus is the main etiological agent of skin lesions. According to our knowledge and as discussed before, it is the first microbiological study focusing on this medicinal plant.

\section{Materials and methods}

\section{Plant material}

Fresh leaves of $E$. pristis were collected in São João del Rei city, District of Rio das Mortes, Minas Gerais state, southeast region of Brazil, on January 24, 2012. The botanical material was identified by Dr. Glauciemar Del-Vechio-Vieira, and a 
voucher specimen (number 207576) was deposited at the Herbarium of the National Museum of Brazil (R), Universidade Federal do Rio de Janeiro, Rio de Janeiro city, Rio de Janeiro state, Brazil. Fresh leaves were dried immediately after the harvest at room temperature $\left(\sim 25^{\circ} \mathrm{C}\right)$ followed by forced ventilation for $90 \%$ - 96\% humidity loss. Dried leaves were triturated by an industrial blender and pulverized in tamise with mesh no 18 to prepare the extracts. The plant name Eryngium pristis Cham. \& Schltdl. has been checked with http://www.theplantlist.org, being a synonym of Eryngium pristis var. abbreviatum $\mathrm{H}$. Wolff (http://www.theplantlist. org/tpl1.1/search?q=Eryngium+pristis+Cham+\%26+Sch ltdl.+) (accessed 07 October 2021). The present research was performed by authorization of the National System for Management of Genetic Heritage (SISGEN) number A1810B1.

\section{Extract preparation}

Dried and powdered material (690 g) was extracted in $95 \%$ ethanol by static maceration for three weeks at room temperature with renewal of solvent every two days. After filtration and solvent evaporation using a rotary vacuum evaporator (R-II Büchi Labortechnik AG) at controlled temperature $\left(40-45^{\circ} \mathrm{C}\right)$, ethanol extract (EE-Ep, $30 \mathrm{~g}$ ) was resuspended in water:ethanol (9:1) followed by liquid/liquid partition with increasing organic solvent polarity to obtain hexane (HF-Ep, $10.8 \mathrm{~g}$ ), dichloromethane (DF-Ep, $2.6 \mathrm{~g}$ ), ethyl acetate (EAF-Ep, $5.0 \mathrm{~g}$ ) and butanol (BF-Ep, $4.8 \mathrm{~g}$ ) fractions [40].

\section{Chemical characterization of HF-Ep and EAF-Ep by Gas Chromatography-Mass Spectrometry (GC-MS)}

HF-Ep and EAF-Ep, the most microbiological active E. pristis fractions tested, were analyzed by GC-MS on a Shimadzu QP2010 Plus (Shimadzu Corporation) system equipped with an AOC-20i auto sampler operating in the electron ionization (EI) mode at $70 \mathrm{eV}$ under the following conditions: Restek Rtx-5MS fused silica capillary column (30 $\mathrm{m} \times 0.25 \mathrm{~mm}$ i.d. $\times 0.25 \mu \mathrm{m}$ film thickness) composed of 5\%-phenyl-95\%-methylpolysiloxane; carrier gas helium (99.999\%) at a constant flow of $1.0 \mathrm{~mL} / \mathrm{min}$; sample injection volume of $0.1 \mu \mathrm{L}$; split less mode; injector temperature $240{ }^{\circ} \mathrm{C}$; and ion-source temperature $280{ }^{\circ} \mathrm{C}$. The oven temperature was programmed to increase from 60 to $84{ }^{\circ} \mathrm{C}$ at $2{ }^{\circ} \mathrm{C} / \mathrm{min}$ and from $84{ }^{\circ} \mathrm{C}$ to $150{ }^{\circ} \mathrm{C}$ at $5{ }^{\circ} \mathrm{C} / \mathrm{min}$. Mass spectra were recorded with a scan interval of $0.5 \mathrm{~s}$ within the mass range 40 - $600 \mathrm{Da}$. The phytochemicals identification presented in HF-Ep and EAF-Ep was based on their retention indices, relative to a homologous series of $n$-alkanes (C7C40) measured on Rtx-5MS capillary column under the same operating conditions. Computer matching to stablish the mass spectra of the compounds was accomplished with the aid of the National Institute of Standards and Technology (NIST) 11 mass spectral database, spectral libraries and literature [41].

\section{In vitro antibacterial activity}

Bacterial strains and culture conditions: To carry out the in vitro antibacterial activity assays, American Type Culture Collection $\left(\right.$ ATCC $\left.^{\circledR}\right)$ and clinical strains selected according to the WHO priority group [31] were tested. Staphylococcus aureus subsp. aureus Rosenbach (ATCC 6538), Staphylococcus aureus subsp. aureus Rosenbach (ATCC 29213), Escherichia coli (Migula) Castellani and Chalmers (ATCC 10536), Escherichia coli (Migula) Castellani and Chalmers (ATCC 25922), Salmonella enterica subsp. enterica (ex Kauffmann and Edwards) Le Minor and Popoff serovar Choleraesuis (ATCC 10708), Salmonella enterica subsp. enterica (ex Kauffmann and Edwards) Le Minor and Popoff serovar Typhimurium (ATCC 13331), Pseudomonas aeruginosa (Schroeter) Migula (ATCC 9027) and Pseudomonas aeruginosa (Schroeter) Migula (ATCC 27853), cited following the ATCC $^{\circledR}$ instructions, were obtained from the Instituto Nacional de Controle de Qualidade em Saúde (INCQS), Fundação Oswaldo Cruz (FIOCRUZ), Rio de Janeiro city, Rio de Janeiro state, Brazil. Methicillin-resistant Staphylococcus aureus (MRSA) 1485279, MRSA 1605677, MRSA 1664534, MRSA 1688441 and MRSA 1830466 clinical strains were isolated of blood obtained from patients attended at Hospital Universitário Clementino Fraga Filho, Universidade Federal do Rio de Janeiro, Rio de Janeiro city, Rio de Janeiro state, Brazil, and phenotypically identified by VITEK ${ }^{\circledR} 2$ automated system (BioMérieux). MRSA clinical strains were added in this study because EE-Ep, HF-Ep and EAF-Ep were active against S. aureus (ATCC 6538) and (ATCC 29213), which provided the better MIC values among the eight ATCC $^{\circledR}$ strains tested. All strains were maintained as suspensions in a $10 \%(w / v)$ skim milk solution containing $10 \%(v / v)$ glycerol at $-20^{\circ} \mathrm{C}$. Before use, all cultures were transferred to Müeller-Hinton Agar (MHA) (Difco Laboratories) at $35 \pm 2{ }^{\circ} \mathrm{C}$ for 18 - $24 \mathrm{~h}$ under aerobic conditions. MRSA were inserted to test because these clinical strains occur on the skin and possess resistance against beta-lactams, represented by the resistance to methicillin.

\section{Determination of Minimal Inhibitory Concentration (MIC) and Minimal Bactericidal Concentration (MBC)}

The broth micro-dilution method according to the Clinical and Laboratory Standards Institute (CLSI) guideline M07-A9 [42], with little adjustments, was employed to determine MIC values of EE-Ep, HF-Ep, DF-Ep, EAF-Ep, BF-Ep, ampicillin (AMP) and chloramphenicol (CHL) (Sigma-Aldrich) against ATCC $^{\circledR}$ and clinical strains aforementioned. The extract and fractions of E. pristis $(12.5 \mathrm{mg} / \mathrm{mL})$ and antibiotic stock solutions $(1.25 \mathrm{mg} / \mathrm{mL})(w / v)$ were prepared in sterilized distilled water and using solvents and diluents recommended by the CLSI's M100-S24 document [43], respectively. In a sterile 96-well microplate, twofold serial dilutions of extract and fractions of E. pristis and AMP and CHL (triplicate) were prepared in Müeller-Hinton broth (MHB) (Difco Laboratories) 
at concentrations ranging from 40 to $5,000 \mu \mathrm{g} / \mathrm{mL}$ and 4 to $500 \mu \mathrm{g} / \mathrm{mL}$, in this order. MIC values above $5,000 \mu \mathrm{g} / \mathrm{mL}$ were not determined. Subsequently, $10 \mu \mathrm{L}$ of standardized bacteria suspension according to the $0.5 \mathrm{McF}$ arland scale were added. After incubation at $35 \pm 2{ }^{\circ} \mathrm{C}$ for 16 to $20 \mathrm{~h}$ under aerobic conditions, $20 \mu \mathrm{L}$ of $1 \mathrm{mg} / \mathrm{mL}$ 2,3,5-triphenyl tetrazolium chloride (TTC) solution (w/v) was used as an indicator of bacterial growth (any color change from purple to pink was recorded as bacterial growth). Posteriorly, the system was incubated for further $30 \mathrm{~min}$, and the MIC was determined. The appropriate controls were performed. After determination of MIC values, MBC was established following the Andrews' protocol [44] by spreading of $10 \mu \mathrm{L}$ of suspensions from wells showing no visible bacterial growth on MHA Petri dishes. After incubation at $35 \pm 2{ }^{\circ} \mathrm{C}$ for 16 to $20 \mathrm{~h}$ under aerobic conditions, the presence or absence of bacterial growth was analyzed. MBC was determined as the lowest concentration of dilutions that prevented the visible bacterial growth after subculture on MHA Petri dishes. Bacterial growth or no bacterial growth on MHA revealed a bacteriostatic or bactericidal effect, respectively.

\section{Acknowledgment}

The current study was supported in part by the Coordenação de Aperfeiçoamento de Pessoal de Nível Superior (CAPES) (Finance Code 001). This study was also financially supported by Fundação de Amparo à Pesquisa do Estado de Minas Gerais (FAPEMIG) (Grant $\mathrm{n}^{\circ}$ CDSAPQ-04680-10), and Pró-Reitoria de Pós-Graduação e Pesquisa of the Universidade Federal de Juiz de Fora (UFJF) (fellowships). We are grateful to Éder Luis Tostes, Jésus de Paula Sarmento and Lívia Mara da Silva of the Faculdade de Farmácia at the UFJF, and to Dr. João Pablo Fortes Pereira of the Instituto de Ciências Biológicas at the UFJF, for the technical support.

\section{References}

1. World Health Organization. Antimicrobial resistance. 2020. https:// www.who.int/en/news-room/fact-sheets/detail/antimicrobialresistance

2. Shallcross LJ, Davies DSC. Antibiotic overuse: a key driver of antimicrobial resistance. Br J Gen Pract. 2014; 64: 604-605. PubMed: https://pubmed.ncbi.nlm.nih.gov/25452508/

3. Unemo M, Nicholas RA. Emergence of multidrug-resistant, extensively drug-resistant and untreatable gonorrhea. Future Microbiol. 2012; 7: 1401-1422.

PubMed: https://pubmed.ncbi.nlm.nih.gov/23231489/

4. World Health Organization. Antibacterial agents in clinical development: an analysis of the antibacterial clinical development pipeline, including tuberculosis. Geneva: WHO. 2017.

5. Thabit AK, Crandom JL, Nicolau DP. Antimicrobial resistance: impact on clinical and economic outcomes and the need for new antimicrobials. Expert Opin Pharmacother. 2015; 16: 159-177. PubMed: https://pubmed.ncbi.nlm.nih.gov/25496207/

6. Zaman SB, Hussain MA, Nye R, Mehta V, Mamun KT, et al. A review on antibiotic resistance: alarm bells are ringing. Cureus. 2017; 9: e1403. PubMed: https://pubmed.ncbi.nlm.nih.gov/28852600/
7. Taiwo MO, Adebayo OS. Plant essential oil: an alternative to emerging multidrug resistant pathogens. J Microbiol Exp. 2017; 5: 00163.

8. Bohlin L, Göransson U, Alsmark C, Wedén C, Backlund A. Natural products in modern life science. Phytochem Rev. 2010; 9: 279-301. PubMed: https://pubmed.ncbi.nlm.nih.gov/20700376/

9. Sukanya SL, Sudisha J, Hariprasad P, Niranjana SR, Prakash HS, et al. Antimicrobial activity of leaf extracts of Indian medicinal plants against clinical and phytopathogenic bacteria. Afr J Biotechnol. 2009; 8: 6677-6682.

10. Newman DJ, Cragg GM. Natural products as sources of new drugs over the nearly four decades from 01/1981 to 09/2019. J Nat Prod. 2020; 83: 770-803.

PubMed: https://pubmed.ncbi.nlm.nih.gov/32162523/

11. Igarashi M. New natural products to meet the antibiotic crisis: a personal journey. J Antibiot. 2019.

12. Chattopadhyay D. Ethnomedicine: A Source of Complementary Therapeutics. Kerala: Research Signpost. 2010.

13. Abreu AC, McBainb AJ, Simões M. Plants as sources of new antimicrobials and resistance-modifying agents. Nat Prod Rep. 2012; 29: 1007-1021.

PubMed: https://pubmed.ncbi.nlm.nih.gov/22786554/

14. da Silva JB, Bessa ME, Mayorga OAS, Andrade VT, Costa YFG, et al. A promising antibiotic, synergistic and antibiofilm effects of Vernonia condensata Baker (Asteraceae) on Staphylococcus aureus. Micro Pathog. 2018; 123: 385-392.

PubMed: https://pubmed.ncbi.nIm.nih.gov/30053603/

15. Erdem SA, Nabavi SF, Orhan IE, Daglia M, Izadi M, et al. Blessings in disguise: a review of phytochemical composition and antimicrobial activity of plants belonging to the genus Eryngium. DARU J Pharm Sci. 2015; 23: 53.

PubMed: https://pubmed.ncbi.nlm.nih.gov/26667677/

16. Del-Vechio-Vieira G, Fernandes LS, Santos BCS, Pires AS, Alves MS, et al. Phenolic constituents and biological properties of Eryngium pristis Cham. \& Schltdl. (Apiaceae). J Chem Pharm Res. 2015; 7: 151-159.

17. Berlinck RGS, de Borges WS, Scotti MT, Vieira PC. A química de produtos naturais do Brasil do século XXI. Quím Nova. 2017; 40: 706-710.

18. Dutra RC, Campos MM, Santos ARS, Calixto JB. Medicinal plants in Brazil: pharmacological studies, drug discovery, challenges and perspectives. Pharmacol Res. 2016; 112: 4-29. PubMed: https://pubmed.ncbi.nlm.nih.gov/26812486/

19. Olano I, Alonso Paz E, Cerdeiras MP, Fermindez J, Ferreira F, et al. Screening of Uruguayan medicinal plants for antimicrobial activity. Part II. J Ethnopharmacol. 1996; 53: 111-115.

20. Paul JH, Seaforth CE, Tikasingh T. Eryngium foetidum L.: a review. Fitoterapia 2011; 82: 302-308.

PubMed: https://pubmed.ncbi.nlm.nih.gov/21062639/

21. Wang P, Su Z, Yuan W, Deng G, Li S. Phytochemical constituents and pharmacological activities of Eryngium L. (Apiaceae). Pharm Crops. 2012; 3: 99-120.

22. García-Ruiz I. Contribución al conocimiento del género Eryngium (Apiaceae) en el estado de Michoacán, México. Acta Bot Mex. 2013; 103: $65-118$

23. Ricardo LM, Paula-Souza J, Andrade A, Brandão MGL. Plants from the Brazilian Traditional Medicine: species from the books of the Polish physician Piotr Czerniewicz (Pedro Luiz Napoleão Chernoviz, 1812-1881). Rev Bras Farmacogn [online]. 2017; 27: 388-400.

24. Koparde AA, Doijad RC, Magdum CS. Natural products in drug discovery - Chapter. In: Koparde AA, Doijad RC, Magdum CS. Pharmacognosy - Medicinal Plants. Karad: IntechOpen. 2019.

25. Karimi S, Lotfipour F, Asnaashari S, Asgharian P, Sarvari Y, et al. Phytochemical analysis and anti-microbial activity of some important 
medicinal plants from north-west of Iran. Iran J Pharm Res. 2019; 18 : 1871-1883.

PubMed: https://pubmed.ncbi.nlm.nih.gov/32184854/

26. The Essential Oil Database - EssOilDB, Eryngium sp., Eryngium species. 2020. http://223.31.159.15/cgi-bin/disc/essoildb/search_2.cgi

27. Daneshzadeh MS, Abbaspour H, Amjad L, Nafchi AM. An investigation on phytochemical, antioxidant and antibacterial properties of extract from Eryngium billardieri F. Delaroche. J Food Meas Charact. 2019

28. Thiem B, Goślińska O, Kikowska M, Budzianowski J. Antimicrobial activity of three Eryngium L. species (Apiaceae). Herba Pol. 2010; 56: $52-58$

29. Sadiq A, Ahmad S, Ali R, Ahmad F, Ahmad S, et al. Antibacterial and antifungal potentials of the solvents extracts from Eryngium caeruleum, Notholirion thomsonianum and Allium consanguineum. BMC Complement Altern Med. 2016; 16: 478.

30. Kuete V. Potential of Cameroonian plants and derived products against microbial infections: review. Planta Med. 2010; 76: 1479-1491. PubMed: https://pubmed.ncbi.nlm.nih.gov/20533165/

31. Zubair M, Ashraf M, Arshad M, Raza A, Mustafa B, et al. Formation and significance of bacterial biofilms. Int $\mathrm{J}$ Curr Microbiol App Sci. 2014; 3: 917-923.

32. Jamal M, Ahmad W, Andleeb S, Jalil F, Imran M, et al. Bacterial biofilm and associated infections. J Chin Med Assoc. 2018; 81: 7-11. PubMed: https://pubmed.ncbi.nlm.nih.gov/29042186/

33. World Health Organization. Prioritization of pathogens to guide discovery, research and development of new antibiotics for drugresistant bacterial infections, including tuberculosis. Geneva: World Health Organization. 2017

34. Sparg SG, Light ME, van Staden J. Biological activities and distribution of plant saponins. J Ethnopharmacol. 2004; 94: 219-243. PubMed: https://pubmed.ncbi.nlm.nih.gov/15325725/

35. Hinds L, Kenny O, Hossain MB, Walsh D, Sheehy E, et al. Evaluating the antibacterial properties of polyacetylene and glucosinolate compounds with further identification of their presence within various carrot (Daucus carota) and broccoli (Brassica oleracea) cultivars using High-Performance Liquid Chromatography with a Diode Array Detector and Ultra Performance Liquid Chromatography-Tandem Mass Spectrometry analyses. J Agr Food Chem. 2017; 65: 7186-7191. PubMed: https://pubmed.ncbi.nlm.nih.gov/28805380/

36. Pandita N, Apraj V. Isolation and identification of bioactive compounds from Ocimum tenuiflorum Linn for Acne Vulgaris. Indian Patent 684/ MUM/2014; 2015

37. Ho CL, Wang EIC, Tseng YH, Liao PC, Lin CN, et al. Composition and antimicrobial activity of the leaf ad twig oils of Listea mushaensis and L. Linii from Taiwan. Nat Prod Commun. 2010; 5: 1823-1828. PubMed: https://pubmed.ncbi.nlm.nih.gov/21213991/

38. Tan M, Zhou L, Huang Y, Wang Y, Hao X, Wang J. Antimicrobial activity of globulol isolated from the fruits of Eucalyptus globulus Labill. Nat Prod Res. 2008; 22: 569-575.

PubMed: https://pubmed.ncbi.nlm.nih.gov/18569693/

39. Kobaisy M, Abramowski Z, Lermer L, Saxena G, Hancock REW, et al. Antimycobacterial polyynes of devil's club (Oplopanax horridus), a North American native medicinal plant. J Nat Prod. 1997; 60: 1210-1213. PubMed: https://pubmed.ncbi.nlm.nih.gov/9392889/

40. Cechinel Filho V, Yunes RA. Estratégias para a obtenção de compostos farmacologicamente ativos a partir de plantas medicinais. Conceitos sobre modificação estrutural para otimização da atividade. Quím Nova. 1998; 21: 99-105.

41. Adams RP. Identification of essential oil components by gas chromatography/mass spectrometry. $4^{\text {th }}$ ed. Illinois: Allured Publishing Corporation. 2007.

42. Clinical and Laboratory Standards Institute, 2012. Methods for dilution antimicrobial susceptibility tests for bacteria that grow aerobically. Approved Standard M07-A9, ninth ed., Wayne, PA.

43. Clinical and Laboratory Standards Institute, 2014. Performance standards for antimicrobial susceptibility testing; Twenty-Fourth Informational Supplement. CLSI document M100-S24. Wayne, PA.

44. Andrews JM. Determination of minimum inhibitory concentrations. J Antimicrob Chemother. 2001; 48: 5-16. 